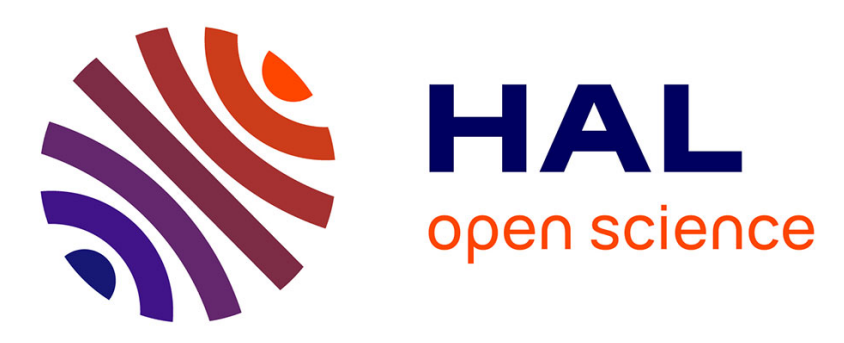

\title{
An optimal dimensioning method of a green wall structure for noise pollution reduction
}

Emmanuel Attal, Bertrand Dubus, Thérèse Leblois, Bernard Cretin

\section{To cite this version:}

Emmanuel Attal, Bertrand Dubus, Thérèse Leblois, Bernard Cretin. An optimal dimensioning method of a green wall structure for noise pollution reduction. Building and Environment, 2021, 187, pp.107362. 10.1016/j.buildenv.2020.107362 . hal-03309605

\section{HAL Id: hal-03309605 https://hal.science/hal-03309605}

Submitted on 30 Jul 2021

HAL is a multi-disciplinary open access archive for the deposit and dissemination of scientific research documents, whether they are published or not. The documents may come from teaching and research institutions in France or abroad, or from public or private research centers.
L'archive ouverte pluridisciplinaire HAL, est destinée au dépôt et à la diffusion de documents scientifiques de niveau recherche, publiés ou non, émanant des établissements d'enseignement et de recherche français ou étrangers, des laboratoires publics ou privés. 


\title{
An Optimal dimensioning method of a green wall structure for noise pollution reduction
}

\author{
Emmanuel Attal ${ }^{\mathrm{a}, \mathrm{b}, *}$, Bertrand Dubus $^{\mathrm{b}}$, Thérèse Leblois $^{\mathrm{a}}$, Bernard Cretin $^{\mathrm{a}}$ \\ ${ }^{a}$ Institut FEMTO-ST, CNRS, Université de Bourgogne Franche-Comté, Besançon, France \\ ${ }^{b}$ Univ Lille, CNRS, Ecole Centrale, Yncrea, Univ Valenciennes, IEMN, UMR 8520 \\ 59046 Lille cedex, France.
}

\begin{abstract}
This paper concern the optimization of a multilayered green wall structure including substrate and foliage in order to reduce as much as possible backward noise reflection and forward transmission from the wall. Each component involved in the wall structure is fully characterized experimentally to get its tranfer matrix. Simulation demonstrated that foliage layer superimposed to substrate layer doesn't affect the transmission losses but contributes greatly to the increase of return losses of the green wall structure. To acheive the best performances in terms of return and forward losses as well as frequency bandwidth, the methods of optimization are discussed including selection of types of materials, thicknesses, arrangement of layers as parameters. Keywords: Noise reduction, Substrate, Foliage, Multi-layer, Return loss, Transmission loss

2010 MSC: 00-01, 99-00
\end{abstract}

\section{Introduction}

Environmental degradation in cities leads public authorities to think about new ecological and sustainable solutions. Among them, the green walls and roofs highlighted their contribution in terms of

\footnotetext{
* Corresponding author

Email address: emmanuel.attal@hotmail.fr (Emmanuel Attal)
} 
5 thermal insulation [1, 2, 3, 4, 5], energy efficiency [6, 7] and acoustics insulation [8, 9, 10, green walls and green roof structures become more and more attractive.

Among the acoustics studies done on green walls, we can quote those performed in situ on modular green wall. Romanova et al [11] employed a paramet10 ric loudspeaker and an acoustic intensity probe to characterise its absorption coefficient. They demonstrated that a high leave area density can significantly improve the absorption coefficient of a green walls system, particularly in the medium and high frequency ranges above $1000 \mathrm{~Hz}$. Lacasta et al [12] implemented their acoustic measurements onto the CadnaA ${ }^{\circledR}$ software in order to

15 foresee the impact of these modular green structure on the road environmental noise. It has been shown that the multiple reflections between the barriers are minimized by the absorption provided by the greenery.

Wong et al [13] evaluated the acoustic insertion loss impacts of several vertical greenery systems of building walls. They highlighted that insertion loss presents a stronger attenuation at middle frequencies because of the absorbing effect of the substrate (decrease around $5-10 \mathrm{~dB}$ ), and a smaller attenuation at higher frequencies (reductions from 2 to $3.9 \mathrm{~dB}$ ) due to the scattering effect from green foliage. The second part of their work carried out in a reverberant room confirmed that the absorption coefficient increases at higher frequencies 25 as well as with greater greenery coverage.

Measurements performed by Azkorra et al [14] confirmed at least the orders of magnitude of those obtained by Wong et al [13].

Insulation studies according to the ISO-140-5 [15] were achieved on a modular green wall structure and on a double skin Green Facade [16. The authors 30 proved that a thin layer improves the sound insulation of $1 \mathrm{~dB}$ in the case of traffic noise, whereas a pinknoise source increases of $3 \mathrm{~dB}$ for a Green Façade.

By numerical approach, Van Renterghem et al [17, evaluated the effect of road traffic on the quietness of the occupants through a green wall building. Three simulations were considered: green roofs, green walls and vegetated low35 height noise barriers positioned near roof edges. They concluded that the effects 
of wall vegetation strongly depend on the assumptions of the chosen material.

Regarding the substrates: some acoustic absorption studies proved their acoustic absorption performances [18. However, according to its composition an important sensitivity against moisture can considerablely affect the absorption

40 coefficient [19, 9, 20].

Some other studies have proved the efficiency of vegetal woolen substrates to increase the transmission loss [21, 22, 23]. As example some hemp concretes can have a transmission loss coefficient varying from 30 to $45 \mathrm{~dB}[24$. To the plant scale, a lot of works demonstrated that by itself, foliage wasn't enough 45 to absorb the noise [20, 25, 26] even if increasing thickness will improve this coefficient [27. However, when it is superimposed to a substrate having a further impedance, the whole system acts as an impedance matching which improves the absorption coefficient [28]. When the foliage impedance becomes of the same order of magnitude than of the substrate, a detuning happens, resulting in a

5o reduction of the absorption coefficient [29]

In the case of U-shaped street, it is important to reduce both the sound coming from vehicles that can be reflected by a building, while maintaining the most optimal sound insulation possible so as to no longer hear outside noise. In this context the application of green walls on buildings to reduce environmental noise

55 is justified. A green wall facade structure is mainly composed of the bearing wall, a substrate layer and a foliage layer.

To our knowledge, only few studies have concerned the impact of the superimposition layer of foliage ontop a substrate layer itself placed against a frontwall of concrete or bricks.

Most of the related studies having been carried out were about in situ characterizations of the sound reduction index [6, 8, 14, 30]. Our research objectives are different and based on a theoretical model enabled to optimize a green wall structure to improve the return and transmission losses.

65

For this purpose we estimate return and transmission losses impact of a plane wave in normal incidence, by associating acoustic models of materials 
which compose the green wall structure. These models deal with quadripolar matrix like which link input face variables (pressure, celerity) to those of output. The ability to simulate multilayers of plants and substrate have been subject 7o to previous articles [28, 31] and will be implemented here, in order to find out a suitable structure which reduces external noise pollution by minimizing the return loss coefficient as well as internal noise by increasing the transmission loss.

\section{Theoretical recalls}

Acoustic properties of a sample focus on the reflection, transmission and attenuation coefficients: to characterize them, we employed the three microphones two load method developed by Salissou et al [32]. This method allows to measure the transfer functions between microphones on both sides of the sample. From these transfer functions, boundary conditions in velocity and pressure are

so deduced, allowing to reconstruct the transfer matrix of the sample. Then, these acoustic coefficients can be evaluated. Transfer matrix parameters $T_{i j}$ were obtained from a homemade impedance tube by calculating the pressure $P$ and particle velocity $V$ of waves on front surface $\mathrm{x}=0$ and back surface $\mathrm{x}=\mathrm{D}$ from acoustic measurements (Eq.(1)).

$$
\left[\begin{array}{l}
P \\
V
\end{array}\right]_{x=0}=\left[\begin{array}{ll}
T_{11}(f) & T_{12}(f) \\
T_{21}(f) & T_{22}(f)
\end{array}\right]\left[\begin{array}{l}
P \\
V
\end{array}\right]_{x=D}
$$

${ }_{85}$ It is assumed that the sample we employed can be described as an effective ideal fluid media because the structure size is very small compared to the acoustic wavelength. Consequently the transfer matrix can be written as:

$$
\left[\begin{array}{cc}
T_{11}(f) & T_{12}(f) \\
T_{21}(f) & T_{22}(f)
\end{array}\right] \simeq\left[\begin{array}{cc}
\cos \left(k_{c} D\right) & j Z_{c} \sin \left(k_{c} D\right) \\
\frac{j \sin \left(k_{c} D\right)}{Z_{c}} & \cos \left(k_{c} D\right)
\end{array}\right]
$$

Where $Z_{c}$ and $k_{c}$ are respectively the characteristic impedance and the wavenumber of the test sample. Further details on the experimental procedures and 
transfer matrix parameters calculations are given in reference [33]. For a sliced sample, in normal incidence and anechoic ending, the reflection $r_{\infty}$ and transmission $t_{\infty}$ pressure coefficients are respectively given by Eq. (3) and (4) 34]

$$
\begin{aligned}
& r_{\infty}(f)=\frac{T_{11}(f)+\frac{T_{12}(f)}{Z_{0}}-Z_{0} T_{21}(f)-T_{22}(f)}{T_{11}(f)+\frac{T_{12}(f)}{Z_{0}}+Z_{0} T_{21}(f)+T_{22}(f)}, \\
& t_{\infty}(f)=\frac{2 e^{j k_{0} D}}{T_{11}(f)+\frac{T_{12}(f)}{Z_{0}}+Z_{0} T_{21}(f)+T_{22}(f)},
\end{aligned}
$$

Where $k_{0}$ and $Z_{0}$ are the wavenumber and impedance of air respectively.

Energy conservation statement performed through a material when an acous-

95 tic wave propagates through it enables to evaluate losses resulting from reflection, transmission and attenuation. Fig.(1) shows this energy flow when it is assumed that the most important part of the attenuated power is obtained at the first transmission. Therefore multiple reflections of the wave inside the material can be neglected [35].

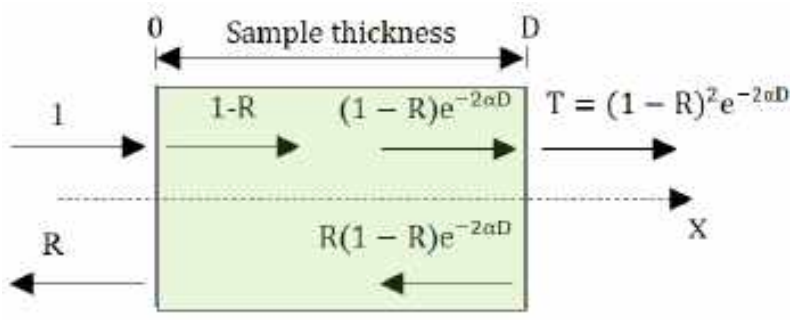

Figure 1: Transmitted $\mathbf{T}$ and reflected $\mathbf{R}$ acoustic powers in a material of given thickness $\mathrm{D}$.

In terms of power
and $t_{\infty}(f)$ by:

$$
\begin{gathered}
R(f)=\left|r_{\infty}(f)\right|^{2}, \\
T(f)=\left|t_{\infty}(f)\right|^{2}=(1-R(f))^{2} e^{-2 \alpha(f) D},
\end{gathered}
$$


Where $\alpha$ is the imaginary part of $k_{c}$ which is the attenuation loss in $N p \cdot m^{-1}$ :

$$
\alpha(f)=\frac{-1}{2 D} \ln \left(\frac{T(f)}{(1-R(f))^{2}}\right)=-\Im m\left(k_{c}\right)
$$

Throughout the rest of the document, losses associated with the previously defined acoustic coefficients (return losses RL [dB], transmission losses TL $[\mathrm{dB}]$ and attenuation $\mathrm{A}\left[\mathrm{dB} \cdot \mathrm{m}^{-1}\right]$ ) will be drawn for a better representation of the materials.

3. Acoustic properties of green wall samples with anechoic termination

Description of the test sample

Vegetation sample considered in this study is a filling of Japanese spindle (Euonymus japonicus) leaves hanging from their original small stems into a sample holder. The size of a leaf is approximately $5 \mathrm{~cm}$ long and $3 \mathrm{~cm}$ wide (Fig $2(a))$.

Although this kind of foliage doesn't have any particular acoustic properties, Japanese spindle is chosen for several reasons: it is easily 115 found in nature; size of its leaves are small in comparison with the tube diameter; its foliage is not altered when separated from the trunk during three days; its foliage is compact and thick allowing for samples of lower porosity and larger thickness.

Leaves filling the sample holder constitute an air filled porosity of $95 \%$ which 120 is estimated by dividing the total volume of the leaves by the internal volume of the sample holder. 
The volume of leaves have been obtained by submerging stems and leaves in a graduated cylinder filled with water and measuring the water level variation.

Coir dust (Fig, 2(b)) is produced after the extraction of coir fibre from the coconut husk and in the production of finished materials from the extracted fibre. It is a brown, spongy particle of low weight which falls out when the fibre is shredded from the husk. Coir dust is about $70 \%$ of the weight of the coconut husk [36. This matter is rich in lignins and tannins, which makes it more resistant and slows down its decomposition [37.

Perlite is a siliceous volcanic natural rock. When heated up to $900^{\circ} \mathrm{C}$, its volume expands by $4-15$ times with a multitude of closed cells formed inside the grains. Expanded perlite (Fig, 2(c)) is lightweight with sharp edges, inert and fire resistant with no emanation. It is composed of millimeter size particles having a crystal-like porous and glassy structure with countless number of pores, each having different micro sizes [38. The loose aggregates have a double porosity and can absorb water up to $300 \%$ of their weight. However it is nonrenewable resource with a bad carbon footprint.

Each sample is successively introduced inside a $8 \mathrm{~cm}$ thick sample holder. A sheet of tulle with fine mesh is added on the top and bottom of the sample holder to fix the geometry of the volume of it.

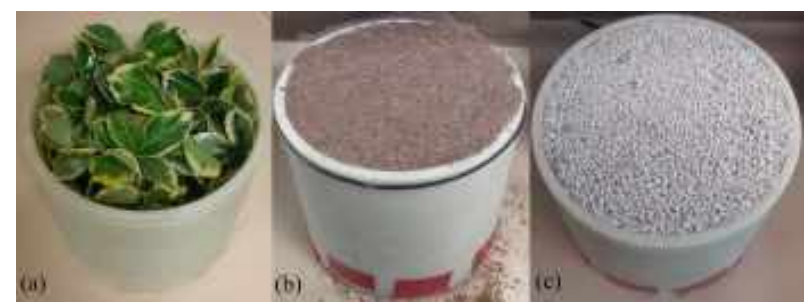

Figure 2: List of samples: (a) Japanese spindle with 5\% foliage (b) Coir peat (c) Perlite. 
Acoustic measurements of test samples

The experimental measurement procedure is the same as the one developed in [33]. Between each measurement, the foliage inside the sample holder is re-mixed. The substrate in the sample holder is carefully removed from the impedance tube (to avoid spilling the substrate) and then reintroduced in either direction. Each measurement on a sample is performed 4 times.

Acoustic properties (return loss, transmission loss and attenuation loss versus frequency) of each sample taken separately are measured in anechoic termination and are displayed in Fig.(3).

Concerning return loss, about between 10 and $15 \mathrm{~dB}$ less power is returned compared to the incident wave in the case of foliage sample. In linear scale, these values correspond to a reflexion coefficient of 0.32 and 0.18 respectively. However perlite and coir dust samples present a return loss weaker than foliage sample.

Transmission loss and attenuation loss are very low in the case of foliage (almost the entire wave power goes through the foliage). These losses are much more important in the case of the two substrates and particularly for coir dust. Indeed losses in this media is about 2.5 times larger than those of perlite. Trends of these coefficients vary monotonically and increase with frequency. Regarding attenuation loss, the curve changes from $20 \mathrm{~dB} \cdot m^{-1}$ at $180 \mathrm{~Hz}$ to $250 \mathrm{~dB} \cdot \mathrm{m}^{-1}$ at $1000 \mathrm{~Hz}$ in the case of coir dust and from $50 \mathrm{~dB} \cdot \mathrm{m}^{-1}$ at $180 \mathrm{~Hz}$ to $100 \mathrm{~dB} \cdot \mathrm{m}^{-1}$ at $1000 \mathrm{~Hz}$ in the case of perlite sample. Conversely for foliage sample, these losses are very weak and negligible compared to the substrates.

These results confirm the insignificant difference of sound level in presence and absence of leaves demonstrated by Mediastika and Binarti [39]. 

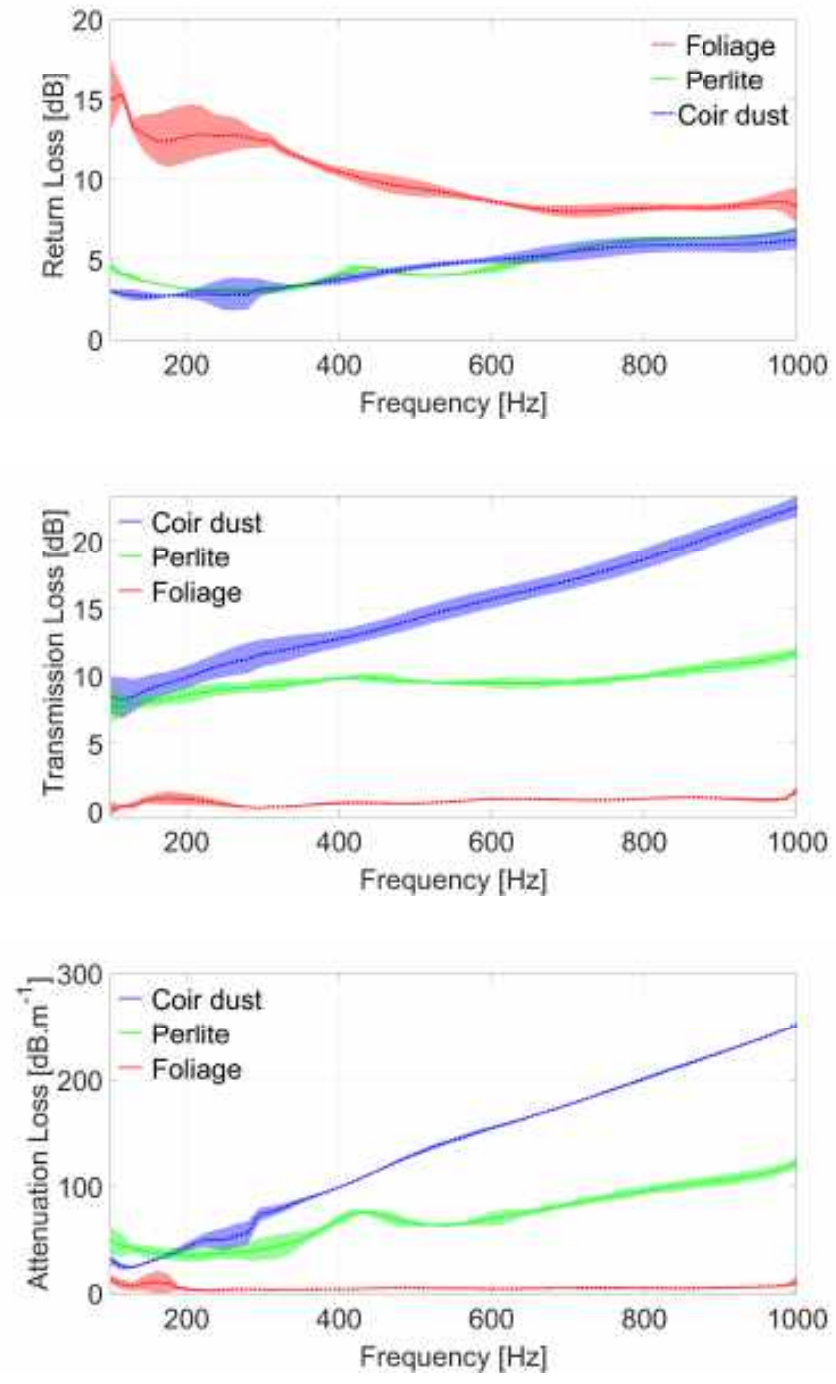

Figure 3: Variation of return loss, transmission loss and attenuation loss versus frequency for $8 \mathrm{~cm}$ thick foliage (red), $8 \mathrm{~cm}$ thick perlite (green) and $8 \mathrm{~cm}$ thick coir dust (blue)

\section{Assembly of the green wall}

Acoustic properties of a bare concrete wall

The previous section has shown that substrates and foliage without rigid ter-

mination have a weak return of the reflected wave. In practice a green wall 
must be placed in contact with a wall (concrete, cement, wood or other), which will modify the acoustic return loss of the structure (Fig.(4)). Before discussing about the impact of a complete green wall on the acoustic coefficients, we will remind the acoustic properties (return loss and transmission loss) of a concrete wall layer.

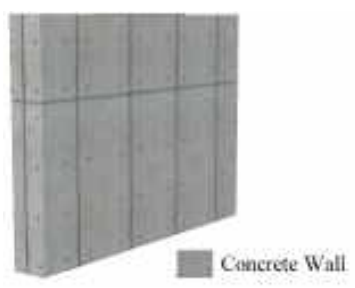

Figure 4: Representation of a concrete wall $20 \mathrm{~cm}$ thick.

Usually, the considered concrete wall has the following properties: $d_{\text {wall }}=20$ $\mathrm{cm}$, density: $\rho_{\text {wall }}=2300 \mathrm{~kg} \cdot \mathrm{m}^{-3}$ and celerity: $c_{\text {wall }}=3200 \mathrm{~m} \cdot \mathrm{s}^{-1}$ [40, 41, 42] . These datas allow to determine the transfer matrix of the rigid concrete wall $\mathbf{T}_{\text {wall }}$ :

$$
\mathbf{T}_{\text {wall }}=\left[\begin{array}{cc}
\cos \left(\frac{2 \pi f d_{\text {wall }}}{c_{\text {wall }}}\right) & j \rho_{\text {wall }} c_{\text {wall }} \sin \left(\frac{2 \pi f d_{\text {wall }}}{c_{\text {wall }}}\right) \\
\frac{j}{\rho_{\text {wall }} c_{\text {wall }}} \sin \left(\frac{2 \pi f d_{\text {wall }}}{c_{\text {wall }}}\right) & \cos \left(\frac{2 \pi f d_{\text {wall }}}{c_{\text {wall }}}\right)
\end{array}\right]
$$

Return and transmission losses versus frequency of such concrete wall are displayed in Fig.(5). Return losses are represented according to the left scale and transmission losses at the right scale. 


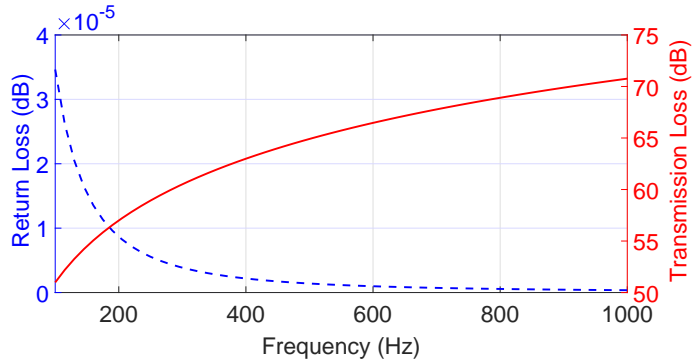

Figure 5: Theoretical acoustic return and transmission losses of a $20 \mathrm{~cm}$ concrete wall. Red dotted line: Return losses and blue continuous line: Transmission losses

Because characteristic impedance of the concrete is very high compared to that of air, return losses are very weak and weaken more and more as the frequency increases. Quite the opposite, transmission losses evolves increasingly from 50 $\mathrm{dB}$ at $100 \mathrm{~Hz}$ until $71 \mathrm{~dB}$ at $1000 \mathrm{~Hz}$. Consequently, the increase of return losses and transmission losses requires at least a second layer which will be presented in the next part.

Simulation of the thickness effect of a substrate positioned on a rigid wall

An absorbing substrate ahead the concrete wall must be placed to increase the return losses over a sufficiently wide bandwidth. Fig.(6) displays two different substrate-concrete wall systems (SCWS): the first SCWS is composed of a perlite layer whereas the second is made of a coir dust layer.

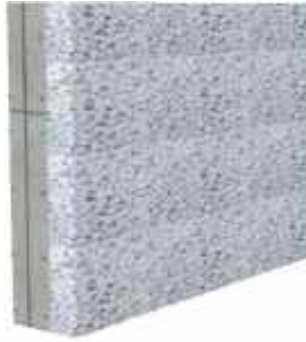

(a)

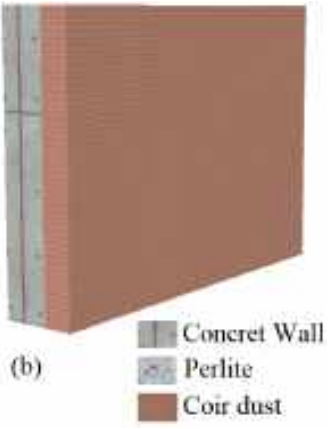

Figure 6: Representation of a $20 \mathrm{~cm}$ thick concrete wall system with substrate (a) Perlite (b) Coir dust. 
Increasing return losses can be accomplished if the surface impedance of the material is close to that of air, which means that sample thickness is equal to $\frac{\lambda}{4}$. In this case there would approach impedance matching.

To understand the phenomena occuring in return losses and transmission losses in the case of substrate layer, a methodology based on the mapping analysis (already employed in a foliage layer [33]) is performed for the two SCWS. 200 Then return losses mapping enables to identify the thickness where the return losses is the weakest. Furthermore, this method allows to optimize the thickness of the substrate to be added in order to increase the return losses. Consequentely, for each sample, transfer matrix depending of the considered thickness layer is calculated from the effective parameters: characteristic impedance $Z_{c}$ 205 and wavenumber $k_{c}$. From these intrinsic parameters, the transfer matrix function of thickness is built and the return losses and transmission losses in rigid condition are mapped. 3D contrast mapping of return losses and transmission losses are obtained by cascading transfer matrix of a substrate with the rigid concrete wall:

$$
\mathbf{T}_{\text {global }}=\mathbf{T}_{\text {substrate }} \mathbf{T}_{\text {wall }}
$$

Return losses mapping of the two substrates are displayed in Fig.(7). These last results were obtained for thickness variations of substrates layer ranging from 0 $\mathrm{cm}$ to $40 \mathrm{~cm}$. 


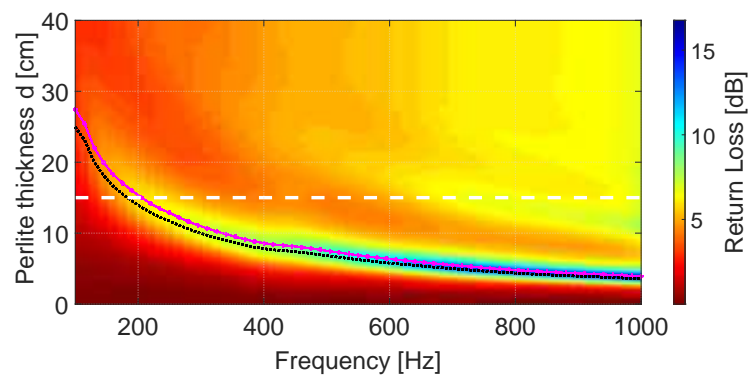

(a) Perlite soil sample

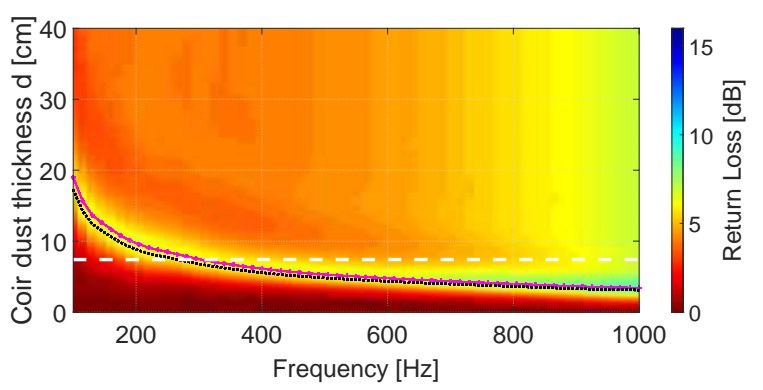

(b) Coir dust soil sample

Figure 7: Variation of simulated return loss $(\mathrm{dB})$ at normal incidence versus sample layer thickness : (a) perlite (b) coir dust. White dotted line: Best localization for the widest possible bandwidth matching. Wall thickness: $20 \mathrm{~cm}$.

Mapping highlights the presence of zones where return losses are more important. These areas appear in blue on the picture. For each mapping, black curve corresponds to the thickness matching condition given by the equation:

$$
D=\frac{c_{m a t}(f)}{4 f}
$$

Where $c_{\text {mat }}$ is the celerity of the considered substrate (perlite or coco dust).

In Fig. (7), curves fit in a satisfactory manner with the most energetic part of return losses in rigid back condition. It can be noted however a slight discrepancy at some frequencies, which means that the matching is not necessarily located 220 at $D=\frac{c_{m a t}}{4 f}$, but can be located at a more or less close thickness (magenta curve). These cartographies shows that return losses values differ in the frequency range and confirm particularly the difficulty to improve return losses at 
lower frequencies. Furthermore the magnitude scale in $\mathrm{dB}$ shows that return loss can be roughly more important at some location in the case of perlite (up 225 to $17 \mathrm{~dB}$ ) than coir dust substrate (up to $9 \mathrm{~dB}$ ).

Fig.(8) reveals that although wideband matching is difficult, it remains possible to obtain an almost homogeneous response according to a certain thickness. In the case of coir dust, a thickness of $7.4 \mathrm{~cm}$ would allow to have return losses ranging from $4 \mathrm{~dB}$ at $175 \mathrm{~Hz}$ up to $7 \mathrm{~dB}$ at $1000 \mathrm{~Hz}$. Below and above this thickness, this objective is more difficult to achieve either in the very low frequencies or in the intermediate frequencies. In the case of perlite a thickness of $15 \mathrm{~cm}$ would allow a more uniform variation over the entire frequency range from $4.5 \mathrm{~dB}$ at $160 \mathrm{~Hz}$ to $7 \mathrm{~dB}$ at $745 \mathrm{~Hz}$.

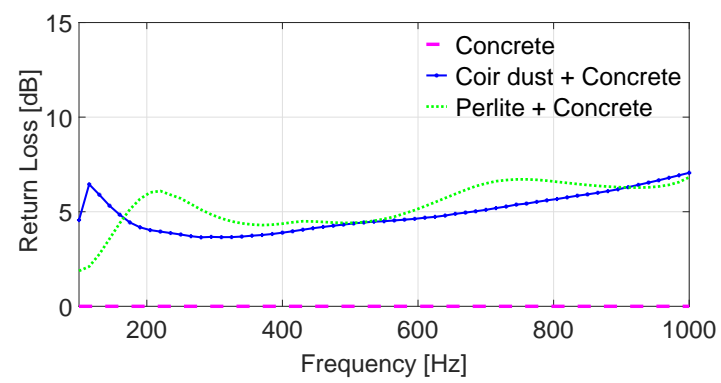

Figure 8: Acoustic return loss of the substrates layer of the substrates layer of $15 \mathrm{~cm}$ perlite and $7.5 \mathrm{~cm}$ coir dust which correspond to the best matching thicknesses over a wide frequency range.

Fig.(9) displays the transmission loss mapping obtained for each substrate. 


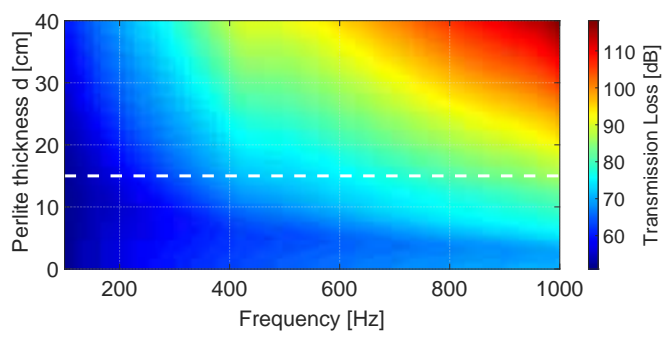

(a) Perlite soil sample

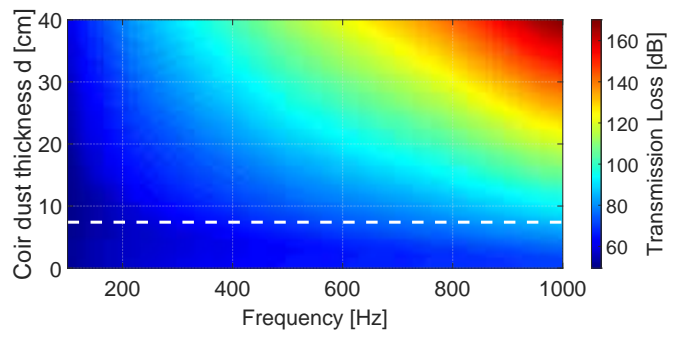

(b) Coir dust soil sample

Figure 9: Variation of simulated transmission losses coefficient in $(\mathrm{dB})$ at normal incidence versus sample layer thickness : (a) perlite (b) coir dust. White dotted line: Best localization for the widest possible bandwidth matching. Wall thickness: $20 \mathrm{~cm}$.

Fig. 10 highlights the importance of the substrate to increase the transmission loss in comparison of the concrete wall alone. Versus frequency, transmisison losses can be increased between $8 \mathrm{~dB}$ and $15 \mathrm{~dB}$ in the case of perlite layer whereas it can vary between $10 \mathrm{~dB}$ and $35 \mathrm{~dB}$ in the case of coir dust layer. So it confirms that, with lower thickness, coir dust is more efficient than perlite.

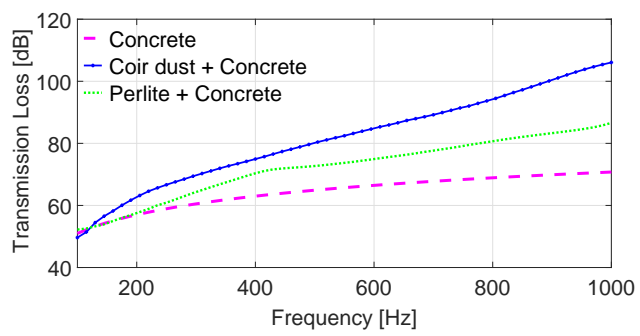

Figure 10: Acoustic transmission loss coefficients of the substrates layer of $15 \mathrm{~cm}$ perlite and $7.5 \mathrm{~cm}$ coir dust which correspond to the best matching thicknesses over a wide frequency range. 
The previous section highlighted that a substrate laid on a concrete wall increases the return losses and transmission losses for a low frequency acoustic wave. However this improvement happens only on a narrow bandwidth (resonances) and furthermore the return losses don't remain very high. In this section we will discuss about the impedance matching between two layers: the substrate and the foliage cover on the concrete wall. Two systems will be studied: the concrete wall, perlite foliage (Fig. (11a)) and the concrete wall, coir dust, foliage (Fig. $(11 \mathrm{~b})$ ). To do this we use the formalism of the assembly of transfer matrices of substrate and foliage type elements which has already proven itself in other 250 publications [33].

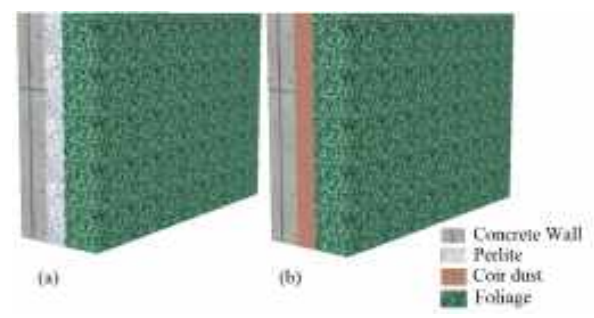

Figure 11: Representation of a green wall system (substrate-foliage) placed on a concrete wall of $20 \mathrm{~cm}$ thick (a) Perlite substrate (b) Coir dust.

First of all, it is important to recall that mapping analysis carried out in a foliage monolayer detailed in the paper [33] has revealed quarter-wave and 3 quarterwave matching effects of this poorly absorbant media. The sound absorption effects of this media began to appear at higher frequencies. The approach studied in this reference was different because it wasn't based on a full optimization approach. This accurate optimization approach is based on the assembly of the concrete wall matrix of constant thickness $\mathbf{T}_{\text {wall }}$ to that of the substrate of variable thickness $\mathbf{T}_{\text {soil }}$ (coir dust or perlite), itself cascaded by that of the foliage $\mathbf{T}_{\text {plants }}$, whose thickness also varies. The overall matrix resulting from 
the cascading of the different elements of the plant wall $\mathbf{T}_{\text {global }}$ is exposed as:

$$
\mathbf{T}_{\text {global }}=\mathbf{T}_{\text {plants }} \mathbf{T}_{\text {soil }} \mathbf{T}_{\text {wall }}
$$

The result allows to represent return losses as a video mapping where each frame represents the thickness of foliage versus frequency for a given substrate thickness.

The thickness variation choice of the different elements was done in such a way as to have a thickness of the whole system (foliage, substrate, concrete wall) which is realistic, while having return losses which are as homogeneous as possible on the entire spectrum, and by seeking to improve the lower frequencies. To be sure of a correct result, it is important that the color of return losses on the cartography tends towards blue color as much as possible over the entire spectrum.

We give an illustrative example of the optimization method, in the case of variable thickness perlite ranging from $0 \mathrm{~cm}$ to $20 \mathrm{~cm}$ (the procedure is exactly the same in the case of coir dust). Fig. (12) displays three examples of perlite thickness configurations superimposed to foliage thickness going from $0 \mathrm{~cm}$ to $40 \mathrm{~cm}$ (including the optimal configuration (Fig. 12b)). The extend thickness scale of foliage was chosen in such a way that higher order modes can be seen in the mapping for different thicknesses of perlite.

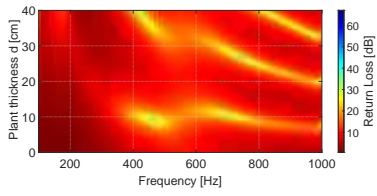

(a) Perlite thickness: $7 \mathrm{~cm}$

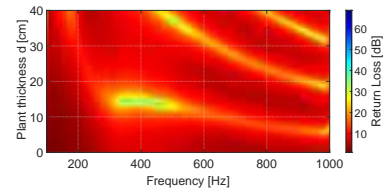

(b) Perlite thickness: $9.3 \mathrm{~cm}$

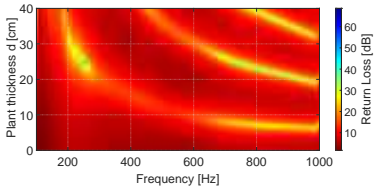

(c) Perlite thickness: $14 \mathrm{~cm}$

Figure 12: Example of return losses mapping for three configurations of perlite thicknesses superimposed to a foliage thickness varying from 0 to $40 \mathrm{~cm}$.

Produced video enables then to deduce the optimal substrate and 
foliage thicknesses where the return losses are greatest. These optimal configurations are directly reported on Fig. 113 .
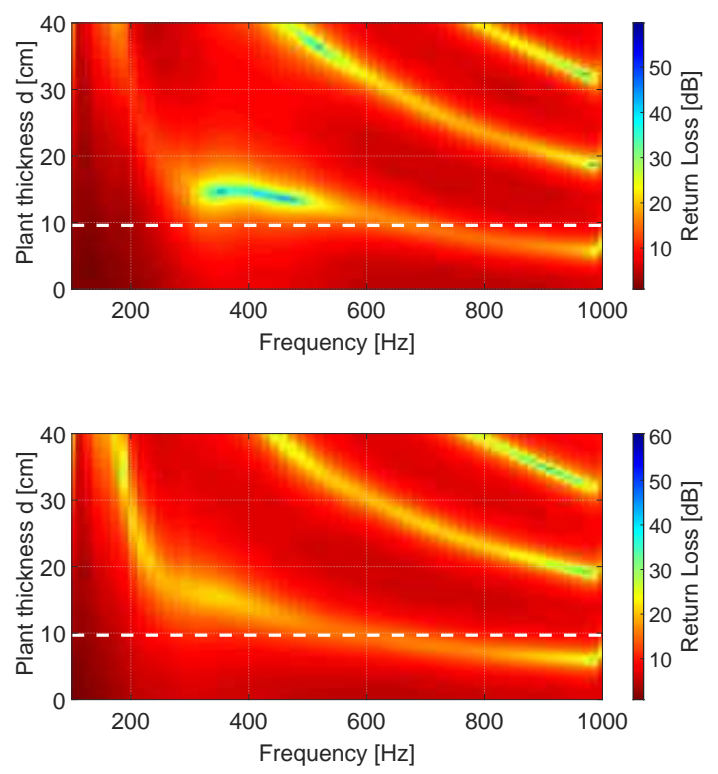

Figure 13: Variation of simulated return loss coefficient in (dB) at normal incidence versus spindle layer thickness: $9.3 \mathrm{~cm}$ thick perlite layer and $9.6 \mathrm{~cm}$ thick foliage (top) and $7.3 \mathrm{~cm}$ thick coir dust layer and $9.7 \mathrm{~cm}$ foliage (bottom). White dotted line: Best localization for the widest possible bandwidth matching. Wall thickness: $20 \mathrm{~cm}$.

The two images presented in Fig.(13) correspond to the best matching between the foliage and each substrate. These locations are established in such a way that the return losses at low frequencies (above $175 \mathrm{~Hz}$ ) are the most favorised while having return losses which are also important in the higher frequencies domain. Moreover, each energy trace present on these cartographies clearly highlights the presence of matching at $D=\frac{(2 n+1) c_{g l o b}(f)}{4 f}$, where $\mathrm{n}=0,1,2$ and $c_{\text {glob }}$ is the global speed of sound between the two media. On both cases, it appears that foliage layer increases the return loss because of its impedance which enough different of those of each substrates. It is obvious that depending of the frequency, a better impedance matching between these two media generates a weaker return loss. For perlite layer combined to foliage 
layer, the best matching enabled a good homogeneity on a relatively large bandwidth is obtained for a perlite thickness of $9.3 \mathrm{~cm}$ and foliage thickness of 9.6 $\mathrm{cm}$. As far as coir dust is concerned, a thickness of $7.3 \mathrm{~cm}$ combined to a foliage thickness of $9.7 \mathrm{~cm}$ enable broadband matching. In this range, return loss vary from $4 \mathrm{~dB}$ at $145 \mathrm{~Hz}$ to $15.5 \mathrm{~dB}$ at $610 \mathrm{~Hz}$, which is an improvement up $8 \mathrm{~dB}$ in comparison without foliage. Roughly, below $265 \mathrm{~Hz}$ it is difficult to obtain matching. To improve matching, it could be better to add an other material layer of intermediate impedance between foliage layer and substrate.

Trends observed in Fig.(14) indicate that the orders of magnitude between these two types of bilayers are almost identical. A coir dust foliage wall would require less thickness than a perlite plant wall for an almost equivalent efficiency. 305 In the case of perlite SCWS, it should be noted a wide stability zone of almost $14 \mathrm{~dB}$ between $340 \mathrm{~Hz}$ and $730 \mathrm{~Hz}$, providing an improvement of at least 7 $\mathrm{dB}$ compared to perlite without foliage layer in this range. For coir dust the plateau zone is not as pronounced as in perlite in this same frequency range, but return loss evolution remains weak. In this same frequency range, the values 31 stay between $12 \mathrm{~dB}$ to $15 \mathrm{~dB}$. 

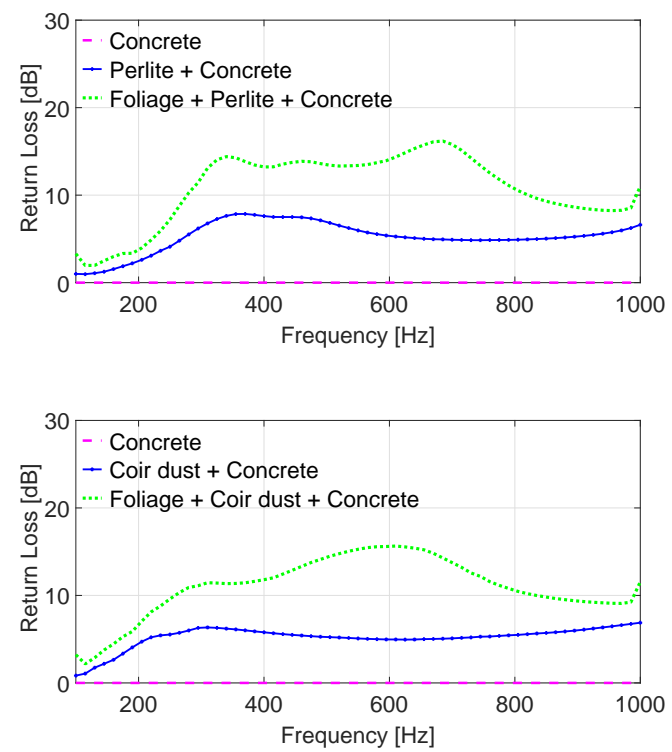

Figure 14: Modulus of return losses: $9.3 \mathrm{~cm}$ thick Perlite soil sample alone and atop $9.6 \mathrm{~cm}$ foliage in $\mathrm{dB}$ (top) and $7.3 \mathrm{~cm}$ thick Coir dust soil sample alone and atop $9.7 \mathrm{~cm}$ foliage (bottom).

Consequently, even if foliage alone is not a good candidate for reducing reflection [33, when foliage is added to a substrate having a higher impedance, the latter have better performance in terms of return loss increases [33, 28].

Assuming that the terminal impedance of a concrete wall is comparable to that of the rigid piston inside the impedance tube, we have represented in Fig. 15 the experimental return loss obtained with the combination of $8 \mathrm{~cm}$ foliage positioned on the different substrate of $8 \mathrm{~cm}$ (each). The numerical curves for these same configurations as well as the optimization curves obtained according the numerical configuration are also present. 

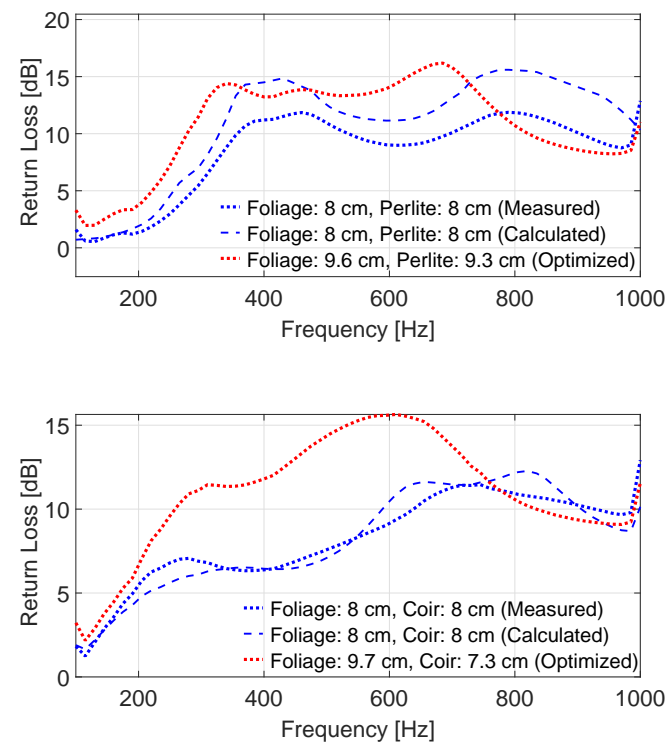

Figure 15: Return losses coefficient of foliage layer ontop substrate layer. Blue dotted lines: measurement, broken line: calculated, red dotted lines: optimization.

A satisfactory agreement between the experimental measurements and simulations of the return losses is obtained. Some slight differences between simulation and experimentation are however highlighted in this figure. The probable origin of such a difference is the orientation of the leaves placed ontop the substrate, which was not the same as at the time of the measurement on the $8 \mathrm{~cm}$ leaves sample obtained separately from the latter. These results also confirm that the predictive optimization models will be given according to a sufficiently reasonable orders of magnitude. Optimization of return losses in the case of a coir dust substrate will be better than in the case of a perlite substrate.

The transmission mapping is deduced after with respect to the thickness of the considered substrate. Transmission losses mapping of each assembly for the optimized thicknesses in the case of return losses are given in Fig.(16). This 
mapping shows that from $250 \mathrm{~Hz}$, transmission losses are about $65 \mathrm{~dB}$. This value means that almost no sound is transmitted.
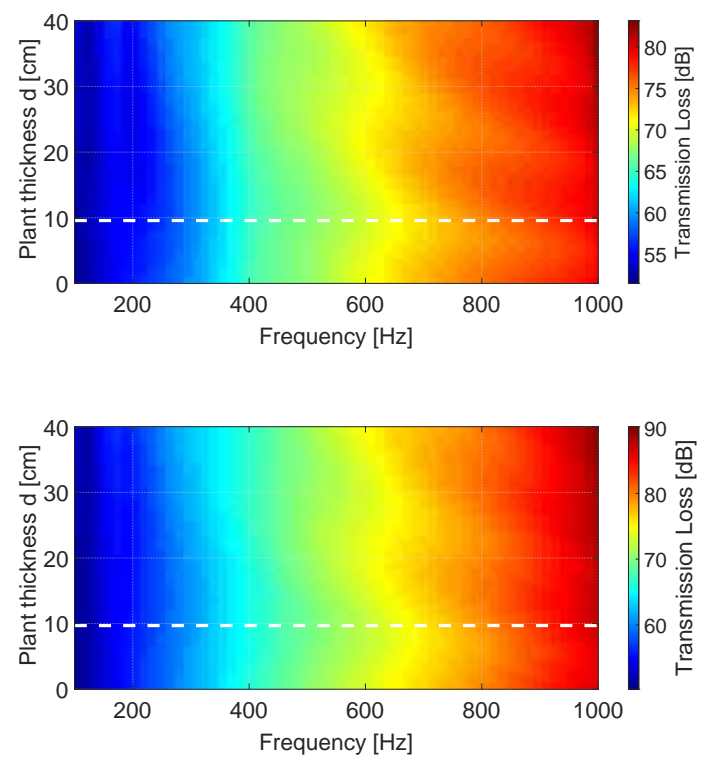

Figure 16: Variation of simulated transmission loss coefficient in $(\mathrm{dB})$ at normal incidence versus spindle layer thickness: $9.3 \mathrm{~cm}$ thick perlite layer and $9.6 \mathrm{~cm}$ thick foliage (top) and $7.3 \mathrm{~cm}$ thick coir dust layer and $9.7 \mathrm{~cm}$ foliage (bottom). White dotted line: Best localization for the widest possible bandwidth matching. Wall thickness: $20 \mathrm{~cm}$.

Fig. 17) displays the evolution of transmission loss of the two different green wall systems for the best configurations obtained previously in the case of the return losses. Transmission loss of the concrete wall represented by the doted line varies continuously between $51 \mathrm{~dB}$ and $72 \mathrm{~dB}$. Continuous blue line represents the transmission loss of each substrate combined to the concrete wall. At lower frequencies (below $400 \mathrm{~Hz}$ ), it appears that the two substrate cover don't seem to have any effects. However above this frequency, the curve increase 345 monotonically until reaching $80 \mathrm{~dB}$ in the case of Perlite and $88 \mathrm{~dB}$ in the case of Coir dust. Consequently the substrate improves the transmission losses and more particularly the coir dust, which brings an improvement of up to $18 \mathrm{~dB}$ at $1000 \mathrm{~Hz}$. Finally the addition of foliage on these different systems don't provide an improvement over the substrate alone. 

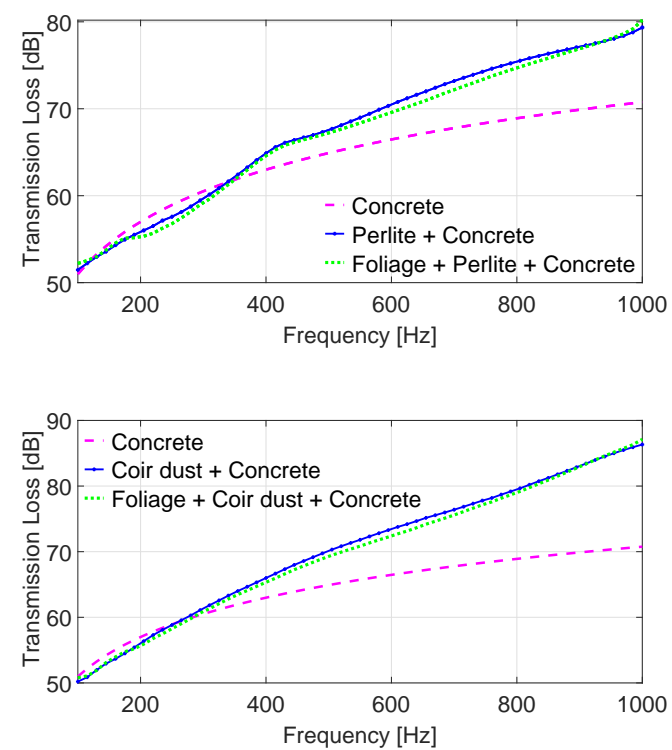

Figure 17: Transmission loss coefficient in dB: $9.3 \mathrm{~cm}$ thick Perlite soil sample alone and atop $9.6 \mathrm{~cm}$ foliage (top) and $7.3 \mathrm{~cm}$ thick Coir dust soil sample alone and atop $9.7 \mathrm{~cm}$ foliage (bottom)

\section{Conclusions and Future work}

Taking into account the dispersion of material properties, the results obtained can be considered very satisfactory as the maximum difference between measurement and simulation is around $3 \mathrm{~dB}$. Two layers green structures applied on a concrete wall may be an efficient solution for noise reduction.

One layer (the substrate) must provide a significant absorption of sound to reduce the transmission whereas the other one (the foliage), rather acts as a matching layer to reduce the returned acoustic power.

The proposed method of optimization requires the exact knowledge of the acoustic properties of the involved materials (namely density, speed of sound, attenuation, characteristic impedance).

3D efficiency mappings allow to determine the best admissible thicknesses of the two layers, for a possible achievement.

The frequency bandwidth can be adjusted or shifted according to the nature of 
the noisy environment and the targeted efficiency

- Return losses are increased with the 2 layers system.

- No improvement in terms of transmission losses is made by the foliage, since the rigid wall-substrate-foliage and rigid wallsubstrate systems give similar results.

In perspectives, several possible paths can be driven:

- The determination of a more suitable choice of materials which can be assembly to the foliage in order to provide a better impedance matching and adequate acoustic dispersion.

375

- The implementation of this study on real walls. This could involve verifying the performance in laboratory or directly in the environment, taking into consideration the effects related to weather, humidity and transport noise.

- Following the results of this study, a complete sketch up of a real street with facades of buildings can be worked out, in order to monitor the mapping of the overall sound level outside and inside the buildings.

\section{Acknowledgments}

Support of this work by ADEME, Yncrea Group and "Hauts-de-France" region is greatly acknowledged. The authors are grateful toward N. Côté and G. Pot and T. Shimizu for their kind advice. 


\section{References}

[1] T. Safikhani, A. M. Abdullah, D. R. Ossen, M. Baharvand, Thermal impacts of vertical greenery systems, Environmental and Climate Technologies 14 (1) (2014) 5-11.

[2] V. Serra, L. Bianco, E. Candelari, R. Giordano, E. Montacchini, S. Tedesco, F. Larcher, A. Schiavi, A novel vertical greenery module system for building envelopes: The results and outcomes of a multidisciplinary research project, Energy and Buildings 146 (2017) 333-352.

[3] L. Libessart, M. A. Kenai, Measuring thermal conductivity of green-walls components in controlled conditions, Journal of Building Engineering 19 (2018) 258-265.

[4] L. Pan, S. Wei, P. Y. Lai, L. Chu, Effect of plant traits and substrate moisture on the thermal performance of different plant species in vertical greenery systems, Building and Environment (2020) 106815.

[5] C. Li, J. Wei, C. Li, Influence of foliage thickness on thermal performance of green façades in hot and humid climate, Energy and Buildings 199 (2019) $72-87$.

[6] G. Pérez, J. Coma, I. Martorell, L. F. Cabeza, Vertical greenery systems (vgs) for energy saving in buildings: A review, Renewable and Sustainable Energy Reviews 39 (2014) 139-165.

[7] H. Omrany, A. Ghaffarianhoseini, A. Ghaffarianhoseini, K. Raahemifar, J. Tookey, Application of passive wall systems for improving the energy efficiency in buildings: A comprehensive review, Renewable and sustainable energy reviews 62 (2016) 1252-1269.

[8] R. Thomazelli, F. D. Caetano, S. R. Bertoli, Acoustic properties of green walls: Absorption and insulation, in: Proceedings of Meetings on Acoustics 22ICA, Vol. 28, Acoustical Society of America, 2016, p. 015017. 
[9] T. Van Renterghem, Green roofs for noise reduction: literature review and new approaches, in: 46th International Congress and Exposition on Noise Control Engineering (Inter-Noise 2017), 2017, pp. 4845-4851.

[10] M. Connelly, M. Hodgson, Sound transmission loss of extensive green roofsfield test results, Canadian Acoustics 36 (3) (2008) 74-75.

[11] A. Romanova, K. V. Horoshenkov, A. Hurrell, An application of a parametric transducer to measure acoustic absorption of a living green wall, Applied Acoustics 145 (2019) 89-97.

[12] A. Lacasta, A. Penaranda, I. Cantalapiedra, C. Auguet, S. Bures, M. Urrestarazu, Acoustic evaluation of modular greenery noise barriers, Urban Forestry \& Urban Greening 20 (2016) 172-179.

[13] N. H. Wong, A. Y. K. Tan, P. Y. Tan, K. Chiang, N. C. Wong, Acoustics evaluation of vertical greenery systems for building walls, Building and Environment 45 (2) (2010) 411-420.

[14] Z. Azkorra, G. Pérez, J. Coma, L. F. Cabeza, S. Burés, J. E. Álvaro, A. Erkoreka, M. Urrestarazu, Evaluation of green walls as a passive acoustic insulation system for buildings, Applied Acoustics 89 (2015) 46-56.

[15] ISO, 140-5: Measurement of sound insulation in buildings and of building elements, part 5: Field measurements of airborne sound insulation of façade elements and façades, in: ISO, International Organization for Standardization, 1998, pp. 1-24.

${ }_{435}^{43}$ [16] G. Pérez, J. Coma, C. Barreneche, A. de Gracia, M. Urrestarazu, S. Burés, L. F. Cabeza, Acoustic insulation capacity of vertical greenery systems for buildings, Applied Acoustics 110 (2016) 218-226.

[17] T. Van Renterghem, M. Hornikx, J. Forssen, D. Botteldooren, The potential of building envelope greening to achieve quietness, Building and Environment 61 (2013) 34-44. 
[18] M. H. Fouladi, M. J. M. Nor, M. Ayub, Z. A. Leman, Utilization of coir fiber in multilayer acoustic absorption panel, Applied Acoustics 71 (3) (2010) 241-249.

[19] C. Fabiani, J. Coma, A. L. Pisello, G. Perez, F. Cotana, L. F. Cabeza, Thermo-acoustic performance of green roof substrates in dynamic hygrothermal conditions, Energy and Buildings 178 (2018) 140-153.

[20] H.-S. Yang, J. Kang, C. Cheal, Random-incidence absorption and scattering coefficients of vegetation, Acta Acustica united with Acustica 99 (3) (2013) 379-388.

${ }_{450}$ [21] P. Glé, E. Gourdon, L. Arnaud, K.-V. Horoshenkov, A. Khan, The effect of particle shape and size distribution on the acoustical properties of mixtures of hemp particles, The Journal of the Acoustical Society of America 134 (6) (2013) 4698-4709.

[22] C. Piégay, P. Glé, E. Gourdon, E. Gourlay, S. Marceau, Acoustical model of vegetal wools including two types of fibers, Applied Acoustics 129 (2018) $36-46$.

[23] P. Glé, T. Blinet, C. Guigou-Carter, Acoustic performance prediction for building elements including biobased fibrous materials, in: Proceedings of the Euronoise, 2018, pp. 27-31.

${ }_{460}$ [24] P. Glé, T. Blinet, C. Guigou-Carter, T. Falwisanner, E. Kadri, F. BouCherifi, Towards a better understanding and knowledge of biobased materials through a new acoustic database, Academic Journal of Civil Engineering 37 (2) (2019) 339-346.

[25] K. V. Horoshenkov, A. Khan, H. Benkreira, Acoustic properties of low 465 growing plants, The Journal of the Acoustical Society of America 133 (5) (2013) 2554-2565. 
[26] F. D'Alessandro, F. Asdrubali, N. Mencarelli, Experimental evaluation and modelling of the sound absorption properties of plants for indoor acoustic applications, Building and Environment 94 (2015) 913-923.

[27] E. Attal, N. Côté, G. Haw, C. Granger, B. Dubus, Caractérisation acoustique et vibratoire d'échantillons inhomogènes de types feuillage ou substrat, in: Congrès Français d'Acoustique, Le Mans, 2016, pp. 2711-2716.

[28] E. Attal, N. Côté, T. Shimizu, B. Dubus, Analysis of environmental and seasonal effects on sound absorption by green wall systems, in: International Congress of Acoustics, Aachen, Germany, 2019, pp. 1-8.

[29] L. Ding, T. Van Renterghem, D. Botteldooren, K. Horoshenkov, A. Khan, Sound absorption of porous substrates covered by foliage: experimental results and numerical predictions, The Journal of the Acoustical Society of America 134 (6) (2013) 4599-4609.

${ }_{480}[30]$ D. Lunain, B. Gauvreau, In-situ evaluation of the acoustic efficiency of a green wall in urban areas, in: INTER-NOISE and NOISE-CON Congress and Conference Proceedings, Vol. 253, Institute of Noise Control Engineering, 2016, pp. 1149-1158.

[31] E. Attal, G. Haw, G. Pot, C. Vasseur, T. Shimizu, C. Granger, C. Croënne, B. Dubus, Experimental characterization of foliage and substrate samples by the three-microphone two-load method, in: INTER-NOISE and NOISECON Congress and Conference Proceedings, Vol. 253, Institute of Noise Control Engineering, 2016, pp. 6715-6722.

[32] Y. Salissou, R. Panneton, O. Doutres, Complement to standard method for measuring normal incidence sound transmission loss with three microphones, The Journal of the Acoustical Society of America 131 (3) (2012) EL216-EL222.

[33] E. Attal, N. Côté, T. Shimizu, B. Dubus, Sound absorption by green walls 
at normal incidence: physical analysis and optimization, Acta Acustica United with Acustica 105 (2) (2019) 301-312.

[34] ASTM, E2611-09: Standard test method for measurement of normal incidence sound transmission of acoustical materials based on the transfer matrix method, in: ASTM, American Society for Testing and Materials, 2009, pp. 1-12.

[35] C. F. Bohren, D. R. Huffman, Absorption and scattering of light by small particles, John Wiley \& Sons, 2008.

[36] E. Tejano, State of the art of coconut coir dust and husk utilization (general overview), Philippine Journal of Coconut Studies 1 (1985) 1-7.

[37] M. Abad, P. Noguera, R. Puchades, A. Maquieira, V. Noguera, Physicochemical and chemical properties of some coconut coir dusts for use as a peat substitute for containerised ornamental plants, Bioresource technology 82 (3) (2002) 241-245.

[38] J. S. Fields, W. C. Fonteno, B. E. Jackson, J. L. Heitman, J. S. Owen, Hydrophysical properties, moisture retention, and drainage profiles of wood and traditional components for greenhouse substrates, HortScience 49 (6) (2014) 827-832.

[39] C. E. Mediastika, F. Binarti, Reducing indoor noise levels using people's perception on greenery, Environmental and Climate Technologies 11 (1) (2013) 19-27.

515 [40] Understand Building Construction, Types of walls: http://www. understandconstruction.com/walls.html. Last accessed on 30/08/2020 (2020).

[41] K. Jones, The Physics Factbook, Density of Concrete: https:// hypertextbook.com/facts/1999/KatrinaJones.shtml. Last accessed on $30 / 08 / 2020(2020)$. 
[42] Speed of Sound in Various Materials, Venom Technologies and Inspection Services: http://venominspection.com/index.php/reference/ speed-of-sound-in-various-materials/. Last accessed on 30/08/2020 (2020). 